\title{
Advances to enhance the utility of traditional wind-driven rain studies already available in multiple regions
}

\author{
Javier Domínguez-Hernández ${ }^{\mathrm{a}}$, José M. Pérez-Bella ${ }^{\mathrm{a}, *}$ \\ a Department of Construction Engineering, Engineering and Architecture School, University of Zaragoza, Zaragoza, Spain.
}

\begin{abstract}
For decades, wind-driven rain studies have been performed in multiple regions to characterise the façade exposure to rainwater penetration. These studies have been invariably conditioned by the exhaustiveness of the available climatic records, traditionally providing scalar exposure results based on the Driving Rain Index. It is only recently that accurate directional analyses have begun to be developed by using, where available, hourly climatic records according to standard ISO 15927-3. Consequently, most countries still lack an accurate characterisation of the most unfavourable exposure that can occur on their building façades. This work presents recent advances and new contributions that allow a novel reinterpretation of the traditional wind-driven rain studies, identifying these exposures from the scalar characterisation already available. Peer-review under the responsibility of the organizing committee of the ICMB21.
\end{abstract}

Keywords: Wind-driven rain; Wind pressure; Directional exposure; Façade design; Watertightness.

\section{Introduction/Background}

The penetration of rainwater into building façades causes deterioration in porous materials, thermal insulation reduction of the building envelope and health problems for occupants. Since the mid-20th century, many efforts have been made to characterise exposure to wind-driven rain (WDR) of building façades in different countries [1]. These studies have mainly characterised an annual Driving Rain Index (aDRI) -see bottom of Fig. 1-, derived from the semi-empirical approach proposed by Lacy, known as 'WDR relationship' [1]. For this purpose, only climatic records of limited exhaustiveness were traditionally available: annual, monthly and more recently, daily data (thus producing aaDRI, maDRI and daDRI values, respectively). In addition, the calculated results have been mainly scalar, which has allowed a simple interpretation by national and regional exposure maps [2-3]. As a result, there are a great number of traditional WDR studies but their exposure results are characterised by poor accuracy and do not reflect the significant variation that occurs in any location depending on the façade orientation [4-5].

In recent years, the standard ISO 15927-3 has established a reference for the quantification of directional WDR exposures (mean annual value and also totalled over the worst WDR period likely to occur in a 3-year return period) [6]. Unfortunately, to quantify the WDR that would impact on a given façade orientation, long series of hourly climatic records (i.e., rainfall and wind velocity) are needed, which are not yet generally available in many regions (see top of Fig. 1, for mean annual exposure).

This work reduces the gap between traditional scalar studies and the exhaustive directional characterisation proposed by the ISO standard, allowing the reinterpretation and reuse of the former. For this purpose, the correlation between the scalar daDRI value and the maximum directional WDR exposure at 28 locations in the Netherlands is analysed. Given that in construction practice it is common to use a similar configuration for all the building's facades (regardless of their orientation), this most unfavourable directional exposure is the most relevant to support the practitioner's decisions concerning façade designs.

\section{Analysis conducted in the Netherlands}

Recent researches conducted at 920 locations in Mexico, Norway and Spain have identified a strong correlation between the scalar daDRI value and the maximum directional daDRI value for each location [7]. This relationship has now also been verified by analysing climatic records collected over 10 years (2010-2019) in 28 Dutch weather stations distributed throughout the country (Fig 1). Both the correlation and the high coefficient of determination obtained ( $\mathrm{R}^{2}$ equal to 0.9818 ) are similar to those already identified in the other countries. Thus, it can be proposed a rough extrapolation for global purposes, equally valid for different

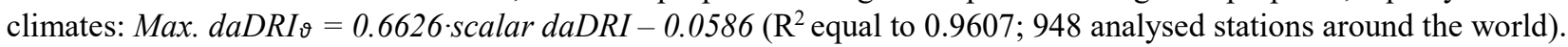

\footnotetext{
* Corresponding author. (+34) 876555 228.jmpb@unizar.es
} 


\section{ICMB21}

In the same Dutch stations, an analysis based on the ISO standard has also been conducted, directionally determining the average annual exposure. As shown in Fig 1, it can also be established a clear relationship between the scalar daDRI value (based on daily data) and the maximum directional exposure from ISO standard (based on hourly data). Similar relationships could be expected from maDRI and aaDRI scalar values, if a maDRI-daDRI or aaDRI-daDRI conversion is previously conducted as indicated in multiple prior studies [2-3].

Thus, it can be concluded that from a simple scalar exposure (daDRI in this example), it is possible to approximate the most relevant exposure for the façade designs of any location. In the Netherlands, the average error due to this approximation reaches only $2.81 \%$ for maximum daDRI ${ }_{\theta}$ values and $3.94 \%$ for maximum $\mathrm{WDR}_{\theta}-\mathrm{ISO}_{\text {- values (with standard deviations of } 1.65 \% \text { and }}$ $2.69 \%$, respectively). This simple approach allows to avoid the calculation effort and the need of hourly climatic records associated with the directional analysis of ISO standard (at least for the context of the usual construction practice), without losing accuracy.

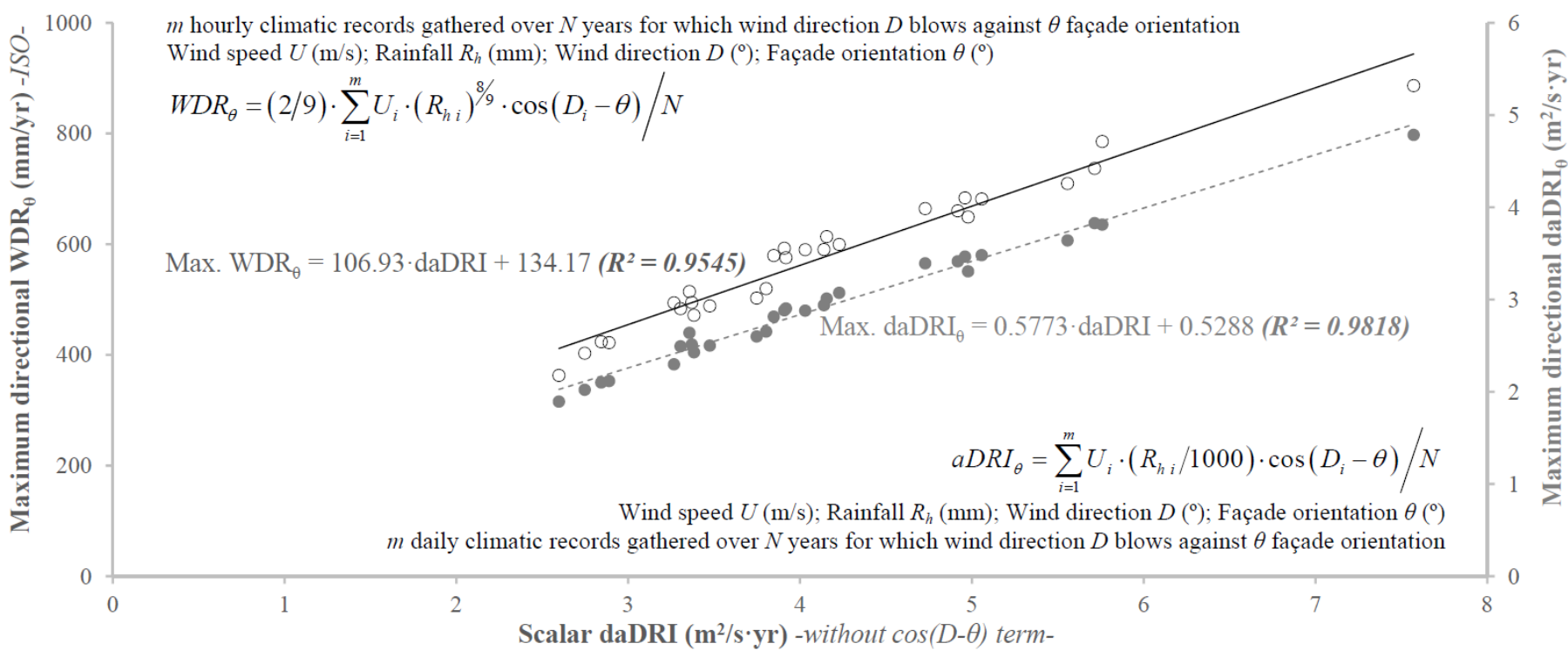

Figure 1. Best-fit correlations between scalar daDRI and both maximum directional exposures daDRI ${ }_{\theta}$ and $\mathrm{WDR}_{\theta}$ in the Netherlands.

\section{Conclusions}

The results obtained in different countries and climates are now also supported by the analysis of Dutch weather stations, thus demonstrating the existence of a strong correlation between the scalar daDRI value of a location and the maximum directional exposure in any of its façades. In the same way, the analysis of 28 Dutch stations shows that it is possible to establish a relationship between traditional scalar values of aDRI and the scalar results determined from hourly records by the ISO 15927-3 standard.

By combining these correlations and considering the relationships identified in the past between aDRI results of different exhaustiveness (i.e., aaDRI, maDRI and daDRI), it is possible to approximate in a functional way the WDR exposure on the most unfavourable façade orientation from simple scalar aDRI results. This procedure of approximation enhances the utility of traditional WDR studies already available in multiple regions and provides a functional tool for the design decisions where until now, only an inaccurate scalar exposure was usable.

\section{References}

[1] Blocken, B., \& Carmeliet, J. (2004). A review of wind-driven rain research in building science. Journal of Wind Engineering and Industrial Aerodynamics, 92(13), 1079-1130.

[2] Domínguez, J., Pérez, J.M., Alonso, M., Cano, E., \& del Coz, J.J. (2017). Assessment of water penetration risk in building facades throughout Brazil. Building Research and Information, 45(5), 492-507.

[3] Pérez, J.M., Domínguez, J., Cano, E., del Coz, J.J., \& Martín, A. (2014). Procedure for a detailed territorial assessment of wind-driven rain and driving-rain wind pressure and its implementation to three Spanish regions. Journal of Wind Engineering and Industrial Aerodynamics, 128, 76-89.

[4] Pérez, J.M., Domínguez, J., Cano, E., del Coz, J.J., \& Alonso, M. (2018). On the significance of the climate-dataset time resolution in characterising winddriven rain and simultaneous wind pressure. Part I: scalar approach. Stochastic Environmental Research and Risk Assessment, 32, 1783-1797.

[5] Pérez, J.M., Domínguez, J., Cano, E., del Coz, J.J., \& Álvarez, F.P. (2018). On the significance of the climate-dataset time resolution in characterising winddriven rain and simultaneous wind pressure. Part II: directional analysis. Stochastic Environmental Research and Risk Assessment, 32, $1799-1815$.

[6] European Committee for Standardization. (2009). EN ISO 15927-3. Hygrothermal performance of buildings. Calculation and presentation of climatic data. Part 3: Calculation of a driving rain index for vertical surfaces from hourly wind and rain data. Brussels.

[7] Pérez, J.M., Domínguez, J., Cano, E., Martínez, J.E., \& del Coz, J.J. (2020). Avoiding the need to directionally determine the exposure to rainwater penetration for façade designs. Building and Environment, 176:106850. 